\title{
CLINICAL EVALUATION OF THE BITING FORCE OF THE MANDIBULAR IMPLANT SUPPORTED OVERDENTURE BY TWO CONVENTIONAL AND TWO MINI IMPLANTS
}

\author{
Ahmad M. Shoeib", Magdy M. Badawy ${ }^{* *}$, Hassan M. Sakr ${ }^{* * *}$, Yasser A. Baraka ${ }^{* * * *}$, \\ Mostafa Y. Farahat****, Mohamad A. Quassem ${ }^{* * * * *}$
}

\begin{abstract}
Objective: The objective of this in vivo study was done to evaluate the biting force when restoring the edentulous mandible with an implant supported overdenture using two conventional implants or two mini implants. Subjects and Methods: Sixteen patients were selected for this study free from any systemic disease or local factor that contraindicate implant placement. Patients were divided into two equal groups: In group I (control group) each patient had received a two conventional implant in the mandible and in group II (test group) each patient had received two mini implant in the mandible. Implants were placed using flapless surgery and immediately loaded by picking up the metal house into the denture. Assessment of bite force was done by force sensor. The evaluation was done at 1 week, and at 3, 6, 9, 12 months. Results: The results showed that the control group had statistically significant higher values of the bite force than the test group. Conclusions: Mandibular implant supported overdenture by two mini implants have shown less retention, biting force, and masticatory efficacy than the overdenture supported by two conventional implants.
\end{abstract}

KEY WORDS: Mini-implants, Implants, Overdenture, Biting forces

\section{INTRODUCTION}

Edentulism is a debilitating and irreversible condition described as the "final marker of disease burden for oral health. Although the prevalence of complete tooth loss has been declined over the past decade, it remains a major disease worldwide, especially among the older adults ${ }^{(1)}$.

The complete denture therapy is associated with many problems as, loss of retention, masticatory inefficiency, mucosal irritation, difficulties in speech, appearance, fractured denture, debonding of teeth, swallowing difficulty, loss or alteration of taste sensation, and nausea and gagging ${ }^{(2)}$. It was demonstrated that more than $56 \%$ of conventional mandibular complete dentures have problems with retention and stability ${ }^{(3)}$.The masticatory function is often poor in the complete denture wearers, which is $10 \%$ to $20 \%$ of that of healthy dentate subjects. Consequently, patients with dentures may have a diet deficient in fiber and vitamins ${ }^{(4)}$.

A major indicator of the functional state of the masticatory system is the biting force. The ability to bite is a function of the muscles of mastication

* Assistant Lecturer, Department of Removable Prosthodontics, Faculty of Dental Medicine, Al-Azhar University, Boys, Cairo

** Professor, Department of Removable Prosthodontics, Faculty of Dental Medicine, Al-Azhar University, Boys, Cairo *** Assistant Professor, Department of Removable Prosthodontics, Faculty of Dental Medicine, Al-Azhar University, Boys, Cairo

**** Assistant Professor, Department of Removable Prosthodontics, Faculty of Dental Medicine, MTI University, Cairo ******ecturer, Department of Removable Prosthodontics, Faculty of Dental Medicine, Al-Azhar University, Boys, Cairo 
(in turn, determined by the central nervous system and feedback from muscle spindles, mechanoreceptors, and nociceptors), the temporomandibular joint, and the dentition.

Interaction of the physical properties of food and the cranio-mandibular structures results in bite force; some biomechanics modify the resultant bite force such as the muscle contraction adaption to the food texture and density (which are largely unknown). Appropriate mastication is a quality-of life-issue, and a primary goal of the implant supported overdenture therapy ${ }^{(5,6)}$.

The maximum bite force level in complete denture wearers has been limited to an extent due to the sensitivity or pain of the mucoperiosteum covering the edentulous mandibular ridge which gets sandwiched in between the dentures and bone. Complete denture wearers reported more frequent pain in the mandible than in the maxilla ${ }^{(7)}$. The bite force was improved after the implant overdenture treatment because as a result of more usage and training of the masseter muscle, the muscle thickness was increased. In addition, the muscle activity in the rest decreased because there is no longer tension needed to stabilize the loose denture during rest ${ }^{(8)}$.

Implants with a diameter above $3.5 \mathrm{~mm}$ are termed as a regular diameter implants overdentures. Implants with a diameter ranged between $3.5 \mathrm{~mm}$ to $3 \mathrm{~mm}$ are termed narrow diameter implants, mini implants are those with a diameter less than $3.0 \mathrm{~mm}^{(9)}$. Mini dental implants have many benefits, such as expanding the bone as they are placed, minimal osteotomy size required, as well as immediate stabilization and loading on the day of placement and so fewer treatment visits. Moreover, flapless placement leads to minimal surgical trauma, and ease of removal in case of failure. Their cost is also significantly less than conventional implants ${ }^{(10)}$. The cost of 4 mini implants is equal to 1 conventional implant $^{(11)}$. A meta-analysis showed that miniimplants tend to provide good patient satisfaction compared to conventional diameter implants in the implant-supported overdentures ${ }^{(12)}$.

The number of implants to be placed for supporting a removable full denture is controversial. Some societies recommend four ${ }^{(13)}$, other recommends two (McGill and York Conesus) ${ }^{(14)}$. A new concept of single midline implant overdenture serves as an inexpensive and less invasive treatment ${ }^{(15)}$.

\section{SUBJECTS AND METHODS}

1. Sixteen male completely edentulous patients aged between 50-60 years were selected from the clinic of Removable Prosthodontics, Faculty of Dental Medicine, Al-Azhar University Cairo, Boys. The patients were free from local or systemic diseases

2. Patient's approval, History taking, and Extra and intra-oral examination, Radiographic evaluation were carried out for each patient

3. The complete denture was constructed for each patient, then the patients were left for 3 months for adaptation to their denture

4. Grouping of the patients: The selected patients were randomly divided into two equal groups:

Group A (Control group): Each patient will receive a mandibular implant supported overdenture by two conventional implants

Group B (Study group): Each patient will receive a mandibular implant supported overdenture by two mini implants

5. Cone Beam Computerized Tomography (CBCT) was taken done before implant placement to assess the bone quality and quantity. A surgical guide was constructed from the 3D model of the CBCT. Implant locations were selected according to Misch ${ }^{(16)}$.The distance between the two mental foramen was divided into five equal distances, namely A, B, C, D, and E from the patient's right side. The implants were placed in the middle of the B \& D locations

6. Prophylactic antibiotic and antiseptic mouthwash was prescribed before surgery 
7. Surgical procedure

A. Bilateral infiltration anesthesia was given to the patient. The position of the prospective implants was marked on the mucosa by a dental probe passing through the sleeves of the surgical guide. Then the radiographic guide was removed, then the mucosa was punched.

B. The surgical guide was placed again to guide the pilot drill in the proper position and angulation through its sleeve, the sequence drills were used to prepare the implant site under copious irrigation, the implants then screwed in place using ratchet

C. In the regular implant group, the ball attachment was fixed to the implant using the ball head abutment driver. The mini implants in the second group were one piece

D. Metal house pick up was done by self-cured acrylic resin

E. Post-surgical instructions and antibiotics were prescribed for each patient

8. Assessment of biting force

A. This is done custom-made device composed of Flexiforce A $301^{\circledR}$ force sensor and Arduino microcontroller with a crystal display. The sensor is calibrated by known weight object for several times, and the sensor is covered by $3 \mathrm{~mm}$ layer of putty rubber base material.

B. The device was placed between the upper and lower first molar. The patient then was instructed to bite as hard as possible for a period of $3 \mathrm{~s}$ three times in succession, with at least $20 \mathrm{~s}$ of resting between each bite. The readings were recorded, and the average bite force was calculated

9. Statistical analysis: The data were collected, tabulated, and statistically analyzed by SPSS ${ }^{\complement}$ 20 for windows. One-way ANOVA was used for the statistical analysis.

\section{RESULTS}

The results of biting force for the left and right side are shown in table (1). For the right and left sides, all values showed a statistically significant difference between the two groups at 6 months, 9 months, and 12 months. For 1 week and 3months, the differences were statistically non-significant.

TABLE (1) Mean values of bite force \pm S.D in Newton in the right and left side

\begin{tabular}{|c|c|c|c|c|c|c|}
\hline \multirow{2}{*}{ Time } & \multicolumn{2}{|c|}{$\begin{array}{c}\text { Mean values of bite force } \pm \text { S.D } \\
\text { in Newtons for the left side }\end{array}$} & \multirow{2}{*}{ P value } & \multicolumn{2}{|c|}{$\begin{array}{c}\text { Mean values of bite force } \pm \text { S.D } \\
\text { in Newtons for the right side }\end{array}$} & \multirow{2}{*}{ P value } \\
\cline { 2 - 3 } & Control group & Test group & & Control group & Test group & \\
\hline 1 week & $99.85 \pm 30.05$ & $72.31 \pm 18.87$ & 0.081 & $84.98 \pm 29.45$ & $65.78 \pm 17.03$ & 0.13 \\
\hline 3 months & $139.4 \pm 17.05$ & $124.9 \pm 34.47$ & 0.3 & $133.1 \pm 40.81$ & $120.2 \pm 32.76$ & 0.55 \\
\hline 6 months & $180.57 \pm 25.11$ & $145.32 \pm 16.51$ & $0.014 *$ & $169.12 \pm 20.94$ & $132.94 \pm 32.68$ & $0.019 *$ \\
\hline 9 months & $219.05 \pm 32.82$ & $159.64 \pm 52.9$ & $0.037 *$ & $204.55 \pm 29.36$ & $151.7 \pm 17.24$ & $0.002 *$ \\
\hline 12 months & $243.75 \pm 40.13$ & $197.14 \pm 20.51$ & $0.011 *$ & $231.54 \pm 19.89$ & $186.23 \pm 32.11$ & $0.012 *$ \\
\hline
\end{tabular}

* Significant difference if $(p>0.05)$, values marked with $(*)$ are significant 


\section{DISCUSSION}

The goal of prosthetic dentistry is to restore the normal function, comfort, and aesthetics of the patient regardless of the atrophy or disease of the stomatognathic system. In an edentulous condition, especially those with resorbed mandibular ridge, it becomes very difficult to achieve this goal with the conventional complete denture therapy. The recent trend toward the use of dental implants to retain and support mandibular dentures has helped to fulfill the functional requirements of the patient with this challenging condition. Ball attachments were used in this study because of its simplicity, ease of handling, minimal chairside time, and relatively low-cost ${ }^{(17)}$.

The sensor used in this study has an advantage over other sensors since soft bite surfaces are recommended for the measurement of the maximum bite force ${ }^{(18)}$. However, one of the drawbacks of the commercial piezoresistive force transducer is the possibility of its damage during use, thus a further protection is needed by covering it with putty rubber base ${ }^{(19)}$.

The results of bite force were low and statistically non-significant for both groups at 1 week, which may be explained by the limitation of mastication by the postoperative pain. The results at 3 months were higher in the conventional implant group but were statistically non-significant from the results of the mini-implant group, which may be explained by limitation of complete biting because there is increased number of the prosthetic adjustments in the early weeks after pick up, and the patients may not close maximally due to fear of prosthesis break. Progressive increase of the bite force is observed in the later periods with statistically significant higher values in the conventional implant group which is possibly attributed to the higher retention value that gives the patient the feeling of comfort and confidence during chewing. Improved retention leads to the improvement of both bite force and masticatory efficiency, retention is extremely important criteria for patient's satisfaction with dentures ${ }^{(20)}$. Loss of retention and stability with mandibular usually causes discomfort and functional limitation, which consequently impacts the oral health-related quality of life in a negative way ${ }^{(21)}$.

\section{CONCLUSION}

Mandibular implant supported overdenture by two mini implants have shown less retention, biting force, and masticatory efficacy than the overdenture supported by two conventional implants.

\section{RECOMMENDATION}

It is advisable to restrict the support of mandibular overdenture by two mini implants to their original use as a provisional restoration until the definitive prosthesis is fabricated with conventional implants or increasing the number of mini implant as a definitive prosthesis

\section{REFERENCES}

1. Lopez C, Saka C, Rada G, Valenzuela D. Impact of fixed implant supported prostheses in edentulous patients: protocol for a systematic review. Brit Med J. 2016;6:1-4.

2. Shiligi K, Nair C, Sajjan M, Mahkija P. Problem solving in complete dentures -An overview. Clin Dent. 2013;1:26-32.

3. Redford M, Drury T, Kingman A, Brown L. Denture use and the technical quality of dental prostheses among persons 18-74 years of age: United States, 1988-1991. J Dent Res. 1996;75:714-25.

4. Allen F, McMillan A. Food selection and perceptions of chewing ability following provision of implant and conventional prostheses in complete denture wearers. Clin Oral Impl Res. 2002;13:320-6.

5. Bakke M. Bite Force and Occlusion. Semin Orthod. 2006;12:120-6.

6. Flanagan D. Bite force and dental implant treatment: a short review. Med Devic. 2017;10:141-8.

7. Kaul A, Goyal D. Bite force comparison of implant-retained mandibular overdentures with conventional complete dentures: An in vivo study. Int J Oral Implant Clin Res. 2011;2:140-4. 
8. Boven G, Raghoebar G, Vissink A, Meijer H. Improving masticatory performance, bite force, nutritional state and patient's satisfaction with implant overdentures: a systematic review of the literature. J Oral Rehabil. 2015; 42:220-33.

9. Preoteasa E, Marina I, Lerner H, Tancu A. Narrow Diameter and Mini Dental Implant Overdentures. Emerging Trends in Oral Health Sciences and Dentistry. $1^{\text {st }}$ ed. Rijeka: InTech; 2015. 242

10. Azzaldeen A, Ahmet A, Ismail H, Georges C, Muhamad A-H. Immediate loading with mini dental implants in the fully edentulous mandible. Int J Dent Health Sci. 2015; 2:1490-9.

11. Griffitts T, Collins C, Collins P. Mini dental implants: an adjunct for retention, stability, and comfort for the edentulous patient. Oral Surg Oral Med Oral Pathol Oral Radiol Endod. 2005;100:e81-4.

12. Sivaramakrishnan G, Sridharan K. Comparison of patient satisfaction with mini-implant versus standard diameter implant overdentures: a systematic review and meta-analysis of randomized controlled trials. Int J Implant Dent. 2017;3:29.

13. Ketabi A, Bornemann G, Ketabi S, Lauer H. Hybrid Prosthetic Treatment of the Edentulous Mandible with Two or Four Implants - A Literature Review. J Dent. 2014;2:1-8.
14. Feine J, G Carlsson, Macentee M, Duncan W, Gizani S, Lund J. The McGill Consensus Statement on Overdentures. Gerodont 2002;19:3-4.

15. Usman J, Raghava R, Kumar R, Ramzi M, Balakrishnan $\mathrm{S}$. Single implant retained mandibular overdenture - a literature review. J Int Oral Health. 2015;1:76:80.

16. Misch C. Contemporary Implant Dentistry. $3^{\text {rd }}$ ed. Missouri: Mosby Elsevier; 2008. 301 p.

17. Alqutaibi A, Kaddah A. Attachments used with implant supported overdenture. Int Dent Med J Adv Res. 2016;1:1-5.

18. Serra M, Manns A. Bite force measurements with hard and soft bite surfaces. J Oral Rehabil. 2013;40:563-8.

19. Nassef T, Tayel M, Elaskary S. A proposed sensory setup to increase computational analysis accuracy for dental applications. Comp Med Appl Int Conf J. 2013:1-10.

20. Alfadda $S$. The relationship between various parameters of complete denture quality and patients satisfaction. J Amer Dent Assoc. 2014;145:941-8.

21. Perea C, Suárez-García M, Del Río J, Torres-Lagares D, Montero J, Castillo R. Oral health-related quality of life in complete denture wearers depending on their socio-demographic background, prosthetic-related factors and clinical condition. Oral Med Oral Pathol. 2013;18:371-80. 